\title{
Extraction Properties of $p$-Methyloxacalix[3]arene Methyl Ether for Alkali Metal Ions
}

\author{
Naoki KANAYA, Shumpei MATSUHASHI and Shoichi KATSUTA* \\ Department of Chemistry, Graduate School of Science, Chiba University, \\ 1-33, Yayoi-cho, Inage, Chiba 263-8522, Japan \\ (Received March 7, 2014; Accepted May 9, 2014)
}

\begin{abstract}
A neutral macrocyclic ligand, $p$-methyloxacalix[3]arene methyl ether (MOC3A-Me), was synthesized and its extraction properties for alkali metal picrates was investigated in a dichloromethane/water system at $25^{\circ} \mathrm{C}$. The alkali metal ions were extracted by MOC3A-Me with a selectivity sequence $\mathrm{Li}^{+}<\mathrm{Na}^{+}<\mathrm{K}^{+} \leq$ $\mathrm{Rb}^{+} \leq \mathrm{Cs}^{+}$, whereas they were little extracted by the parent oxacalix[3]arene which contains free hydroxyl groups. From extraction equilibrium analysis, MOC3A-Me (L) was found to extract each alkali metal picrate $\left(\mathrm{M}^{+} \mathrm{A}^{-}\right.$) by the reaction $\mathrm{M}^{+}{ }_{\mathrm{w}}+\mathrm{L}_{\mathrm{o}}+\mathrm{A}_{\mathrm{w}}^{-} \rightleftarrows \mathrm{ML}^{+} \mathrm{A}^{-}$, where subscripts ' $\mathrm{o}$ ' and ' $\mathrm{w}$ ' denote the organic and aqueous phases, respectively. The logarithmic values of the extraction equilibrium constants were determined to be $1.73,2.12,2.89,3.01$, and 3.07 for $\mathrm{Li}^{+}, \mathrm{Na}^{+}, \mathrm{K}^{+}, \mathrm{Rb}^{+}$, and $\mathrm{Cs}^{+}$, respectively. The structures and thermodynamic stabilities of the $\mathrm{ML}^{+}$complexes in the gas phase were evaluated by DFT calculations to discuss factors determining the cation selectivity of MOC3A-Me.
\end{abstract}

\section{Introduction}

Crown ethers and calixarenes are widely studied as synthetic ionophores. In contrast, hexahomotrioxacalixarenes, commonly called oxacalix[3]arene, have not yet been studied well but are attracting increasing interest [1]. The solvent extraction properties of $p$-tert-butyloxacalix[3]arene derivatives for various metal ions were investigated qualitatively based on the percent extraction for given conditions [2-8]. For example, methyl and ethyl ethers of p-tert-butyloxacalix[3]arene are known to show $\mathrm{K}^{+}$selectivity in the extraction of alkali metal picrates in a dichloromethane/water system [3,5]. To obtain more insight into the cation selectivity of oxacalix[3]arenes, quantitative data based on the equilibrium constants are necessary. In this study, we synthesized $p$-methyloxacalix[3]arene methyl ether (MOC3A-Me, Figure 1) and its extraction properties for alkali metal picrates were investigated in the dichloromethane/water system at $298 \mathrm{~K}$ $\left(25^{\circ} \mathrm{C}\right)$. The extraction equilibrium constants were determined from analysis of the equilibria. To enable discussion of the factors determining the cation selectivity of MOC3A-Me, the structures and thermodynamic stabilities of MOC3A-Me - alkali

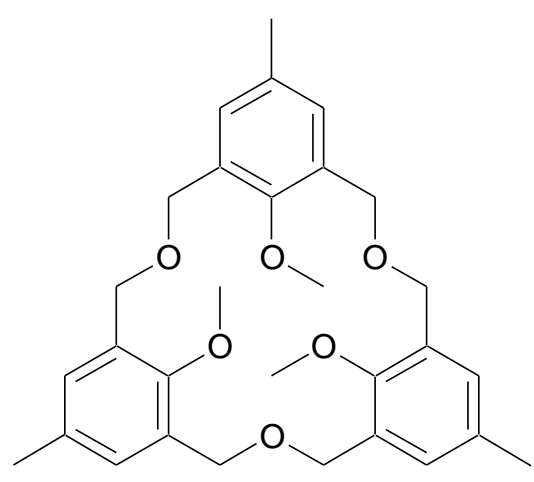

Figure 1. Structural formula of MOC3A-Me. 
metal ion complexes in the gas phase were evaluated by DFT calculations.

\section{Experimental}

\subsection{Reagents and instruments}

Water was deionized and further purified through a Milli-Q Labo system (Millipore). Dichloromethane of guaranteed-reagent grade was distilled before use. Acetone of guaranteed-reagent grade was dried over molecular sieves 4A and distilled just before use. Potassium carbonate of guaranteed reagent grade was dried over phosphorus pentoxide under vacuum for one day. Aqueous solutions of alkali metal picrates were prepared as described previously [9]. Hydrochloric acid of super special grade (Kanto Chemical Co.) was used as received. All other reagents were obtained from commercial sources as guaranteed or extra-pure grade and used without further purification.

Characterization of MOC3A-Me was carried out using a JEOL JNM-ECS400 FT-NMR spectrometer, a Thermo Fisher Exactive mass spectrometer, and a Perkin-Elmer PE2400II elemental analyzer at the Center for Analytical Instrumentation, Chiba University. UV-Vis absorption spectra were recorded on a Beckman DU-640 spectrophotometer. Determination of alkali metals was performed with a Hitachi Z-5000 polarized Zeeman atomic absorption spectrophotometer in flame atomic absorption mode $(\mathrm{K}$ and $\mathrm{Rb})$ or emission mode ( $\mathrm{Li}, \mathrm{Na}$, and $\mathrm{Cs}$ ).

\subsection{Preparation of MOC3A-Me}

The synthetic work was conducted under a nitrogen atmosphere and the solvents used were degassed by ultrasound just before use. $p$-Methyloxacalix[3]arene was synthesized according to the literature [4]. A mixture of $p$-methyloxacalix[3]arene $\left(0.188 \mathrm{~g}, 4.17 \times 10^{-4} \mathrm{~mol} \mathrm{dm}^{-3}\right)$, potassium carbonate $(1.15 \mathrm{~g}, 8.32$ $\left.\times 10^{-3} \mathrm{~mol} \mathrm{dm}^{-3}\right)$ and iodomethane $\left(4.56 \mathrm{~g}, 3.21 \times 10^{-2} \mathrm{~mol} \mathrm{dm}^{-3}\right.$ ) was stirred under reflux in acetone (20 $\left.\mathrm{cm}^{3}\right)$ for $24 \mathrm{~h}$. The reaction mixture was poured into dilute hydrochloric acid $\left(0.12 \mathrm{~mol} \mathrm{dm}{ }^{-3}, 10 \mathrm{~cm}^{3}\right)$ and the product was extracted with dichloromethane $\left(20 \mathrm{~cm}^{3}\right)$. The dichloromethane solution was washed three times with water, and then evaporated and dried under vacuum, leaving MOC3A-Me as a white powder (0.158 g, yield $74 \%$ ). ${ }^{1} \mathrm{H}$ NMR (400 MHz, $\left.\mathrm{CDCl}_{3}, \mathrm{TMS}\right): \delta 2.27$ (s, 9H, $\mathrm{CH}_{3}$ ), $3.18\left(\mathrm{~s}, 9 \mathrm{H}, \mathrm{OCH}_{3}\right), 4.45$ $\left(\mathrm{s}, 12 \mathrm{H}, \mathrm{CH}_{2}\right), 7.07$ (s, 6H, CH); ${ }^{13} \mathrm{C}$ NMR (100 MHz, $\left.\mathrm{CDCl}_{3}, \mathrm{TMS}\right): \delta$ 20.76, 62.11, 66.47, 155.86, 131.17, 131.48, 132.71. HR MS (ESI) found: $\mathrm{m} / \mathrm{z}$ 515.2396. Calc. for $\mathrm{C}_{30} \mathrm{H}_{36} \mathrm{O}_{6} \mathrm{Na}[\mathrm{M}+\mathrm{Na}]^{+}: \mathrm{m} / \mathrm{z}$ 515.240960 (the sodium detected in the ESI-MS spectrum came from the instrument system). Anal. found: C, 72.47; H, 7.33\%. Calc. for $\mathrm{C}_{30} \mathrm{H}_{36} \mathrm{O}_{6}: \mathrm{C}, 73.17 ; \mathrm{H}, 7.32 \%$. UV: $\lambda_{\max }\left(\mathrm{CH}_{2} \mathrm{Cl}_{2}\right) 281 \mathrm{~nm}\left(\varepsilon=3.9 \times 10^{3} \mathrm{dm}^{3}\right.$ $\left.\mathrm{mol}^{-1} \mathrm{~cm}^{-1}\right)$.

\subsection{Extraction of alkali metal picrates with MOC3A-Me}

Equal volumes of a dichloromethane solution of MOC3A-Me $\left(6 \times 10^{-4}-1 \times 10^{-2} \mathrm{~mol} \mathrm{dm}^{-3}\right)$ and an aqueous solution of an alkali metal picrate $\left(2 \times 10^{-3}-7 \times 10^{-3} \mathrm{~mol} \mathrm{dm}^{-3}, \mathrm{pH} 7.0-7.4\right)$ were placed in a Teflon FEP centrifuge tube. The two-phase mixture was equilibrated by shaking the tube mechanically for $1 \mathrm{~h}$ at 250 strokes per min at $298.2 \pm 0.2 \mathrm{~K}$. After the organic and aqueous phases were separated by centrifugation at $3000 \mathrm{rpm}$, the concentration of the alkali metal in the organic phase was determined as follows. An aliquot of the organic phase was transferred to another centrifuge tube in which water of the same volume as the organic phase was placed, and the tube was shaken for $30 \mathrm{~min}$; by this operation, the alkali metal in the organic phase was completely back extracted into the water. The alkali metal 
concentration was determined with an atomic absorption spectrophotometer after addition of hydrochloric acid (final concentration of $\mathrm{HCl}, 0.06 \mathrm{~mol} \mathrm{dm}^{-3}$ ). The concentration of the alkali metal in the aqueous phase was calculated based on the mass balance, and the distribution ratio $(D)$ of the alkali metal was determined as the ratio of the molar concentration in the organic phase to that in the aqueous phase. Blank extraction with pure dichloromethane was negligibly small.

\subsection{DFT calculations}

DFT (B3LYP $[10,11])$ calculations for MOC3A-Me and its complexes with alkali metal ions $\left(\mathrm{Na}^{+}\right.$, $\mathrm{K}^{+}, \mathrm{Rb}^{+}$, and $\left.\mathrm{Cs}^{+}\right)$in the gas phase were performed with the Gaussian 03 program package [12]. The equilibrium geometries and electronic energies were calculated with a 6-31G(d) standard basis set for $\mathrm{C}, \mathrm{H}$, $\mathrm{O}$, and $\mathrm{Na}$ atoms and a LANL2DZ effective core potential basis set [13] for $\mathrm{K}, \mathrm{Rb}$, and $\mathrm{Cs}$ atoms. The thermal corrections to Gibbs free energies at $298 \mathrm{~K}$ and 1 atm were obtained from frequency calculations using a scaling factor of 0.9804 [14]. Equilibrium geometry in dichloromethane was also calculated using the Onsager model $[15,16]$ for MOC3A-Me and its $\mathrm{Na}^{+}$complex; the geometries in dichloromethane were confirmed to be almost the same as those in the gas phase.

\section{Results and Discussion}

Initially, the distribution of MOC3A-Me was evaluated in the dichloromethane/water system. When the dichloromethane solution of MOC3A-Me $\left(9 \times 10^{-3} \mathrm{~mol} \mathrm{dm}^{-3}\right)$ was equilibrated with an equal volume of water at $298 \mathrm{~K}$ (shaking time, $1 \mathrm{~h}$ ), the UV-Vis absorption spectrum of MOC3A-Me in the organic phase practically did not change and no light absorption of MOC3A-Me was observed in the aqueous phase. This result shows that MOC3A-Me is stable in this system and so hydrophobic that the distribution from the dichloromethane phase to the aqueous phase is negligible.

Although the alkali metal picrates were more or less extracted by MOC3A-Me as described below, they were little extracted by the parent oxacalix[3]arene which contains free hydroxyl groups ( $p$-methyloxacalix[3]arene). This result is the same as that reported for $p$-tert-butyloxacalix[3]arene [4]. It appears that the strong intramolecular hydrogen bonds between the hydroxyl groups make the oxygen atoms unable to bind to the alkali metal ions.

The extraction of an alkali metal ion $\left(\mathrm{M}^{+}\right)$with MOC3A-Me as a ligand $(\mathrm{L})$ and picrate as a counter ion $\left(\mathrm{A}^{-}\right)$can be expressed as

$$
\begin{aligned}
& \mathrm{M}_{\mathrm{w}}^{+}+\mathrm{L}_{\mathrm{o}}+\mathrm{A}_{\mathrm{w}}^{-} \rightleftarrows \mathrm{ML}^{+} \mathrm{A}_{\mathrm{o}}^{-} \\
& K_{\mathrm{ex}}=\left[\mathrm{ML}^{+} \mathrm{A}^{-}\right]_{\mathrm{o}} /\left(\left[\mathrm{M}^{+}\right]_{\mathrm{w}}[\mathrm{L}]_{\mathrm{o}}\left[\mathrm{A}^{-}\right]_{\mathrm{w}}\right)
\end{aligned}
$$

where $\mathrm{ML}^{+} \mathrm{A}^{-}$represents the ion pair of the $\mathrm{ML}^{+}$complex with $\mathrm{A}^{-}$; the subscripts ' $\mathrm{o}$ ' and ' $\mathrm{w}$ ' refer to the organic and aqueous phases, respectively; $K_{\mathrm{ex}}$ is the extraction equilibrium constant. When the distribution ratio, $D$, of the alkali metal is approximately equal to $\left[\mathrm{ML}^{+} \mathrm{A}^{-}\right]_{\mathrm{o}} /\left[\mathrm{M}^{+}\right]_{\mathrm{w}}$, the following equation is derived from Eq. (2):

$$
D /\left[\mathrm{A}^{-}\right]_{\mathrm{w}}=K_{\mathrm{ex}}[\mathrm{L}]_{\mathrm{o}}
$$


The $[\mathrm{L}]_{\mathrm{o}}$ and $\left[\mathrm{A}^{-}\right]$values can be calculated from the following equations:

$$
[\mathrm{L}]_{\mathrm{o}}=[\mathrm{L}]_{\mathrm{t}}-\left[\mathrm{ML}^{+} \mathrm{A}^{-}\right]_{\mathrm{o}}
$$

$$
\left[\mathrm{A}^{-}\right]_{\mathrm{w}}=[\mathrm{A}]_{\mathrm{t}}-\left[\mathrm{ML}^{+} \mathrm{A}^{-}\right]_{\mathrm{o}}
$$

where the subscript ' $\mathrm{t}$ ' denotes the total concentration. The $\log \left(D /\left[\mathrm{A}^{-}\right]_{\mathrm{w}}\right) v s . \log [\mathrm{L}]_{\mathrm{o}}$ plots are shown in Figure 2. Each plot gives a straight line of slope 1 as expected from Eq. (3), proving that the extracted species are of the form $\mathrm{ML}^{+} \mathrm{A}^{-}$. The $\log K_{\mathrm{ex}}$ values were determined and are given in Table 1.

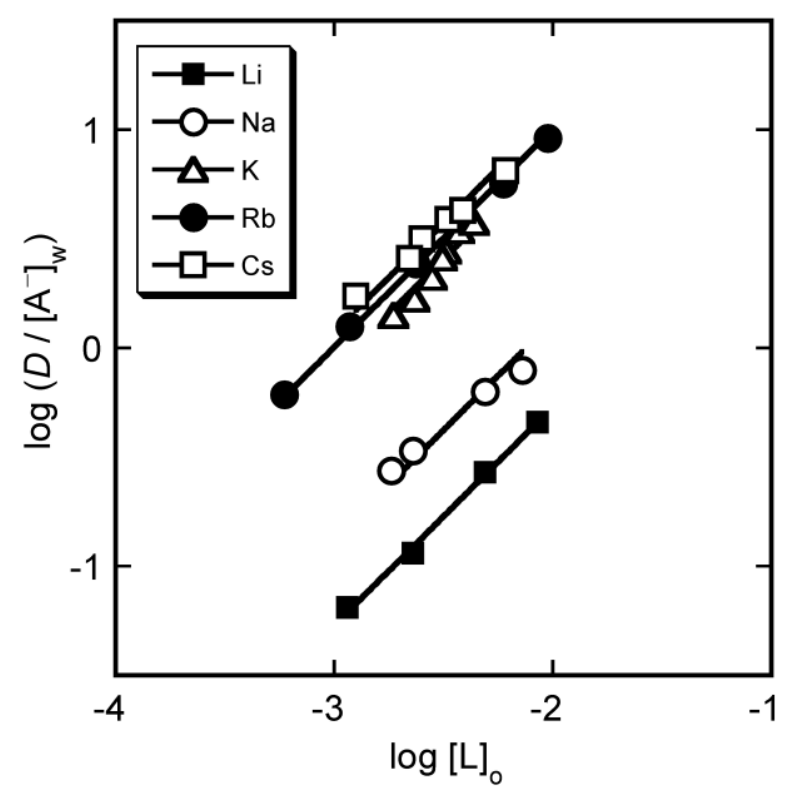

Figure 2. Plots of $\log \left(D /\left[\mathrm{A}^{-}\right]_{\mathrm{w}}\right) v s . \log [\mathrm{L}]_{\mathrm{o}}$ for the extraction of alkali metal picrates with MOC3A-Me in dichloromethane.

Table 1. Equilibrium constants and standard Gibbs free energy changes in the extraction system for alkali metal picrates $\left(\mathrm{M}^{+} \mathrm{A}^{-}\right)$with MOC3A-Me (L) in dichloromethane (o) at $298 \mathrm{~K}$.

\begin{tabular}{ccccc}
\hline $\mathrm{M}^{+}$ & $\log K_{\mathrm{ex}}$ & $\begin{array}{c}\Delta G_{\text {ex }}^{\circ} \\
(\mathrm{kJ} / \mathrm{mol})\end{array}$ & $\begin{array}{c}\Delta G_{\mathrm{tr}, \mathrm{M}+\mathrm{A}}^{\circ} \\
(\mathrm{kJ} / \mathrm{mol})\end{array}$ & $\begin{array}{c}\Delta G^{\circ}{ }_{\mathrm{MLA}, \mathrm{o}}{ }^{b} \\
(\mathrm{~kJ} / \mathrm{mol})\end{array}$ \\
\hline $\mathrm{Li}^{+}$ & $1.73 \pm 0.02$ & -9.88 & - & - \\
$\mathrm{Na}^{+}$ & $2.12 \pm 0.06$ & -12.1 & 61.8 & -73.9 \\
$\mathrm{~K}^{+}$ & $2.89 \pm 0.03$ & -16.5 & 36.0 & -52.5 \\
$\mathrm{Rb}^{+}$ & $3.01 \pm 0.02$ & -17.2 & 27.6 & -44.8 \\
$\mathrm{Cs}^{+}$ & $3.07 \pm 0.04$ & -17.5 & 25.7 & -43.2 \\
\hline
\end{tabular}

${ }^{a}$ Standard Gibbs free energy change for the reaction $\mathrm{M}_{\mathrm{w}}^{+}+\mathrm{A}_{\mathrm{w}}^{-} \rightarrow \mathrm{M}_{\mathrm{o}}^{+}+\mathrm{A}_{\mathrm{o}}^{-}$; Ref. 18.

${ }^{b}$ Standard Gibbs free energy change for the reaction $\mathrm{M}_{\mathrm{o}}^{+}+\mathrm{L}_{\mathrm{o}}+\mathrm{A}_{\mathrm{o}}^{-} \rightarrow \mathrm{ML}^{+} \mathrm{A}_{\mathrm{o}}^{-}$. 
The selectivity of MOC3A-Me for the alkali metal ions is as follows: $\mathrm{Li}^{+}<\mathrm{Na}^{+}<\mathrm{K}^{+} \leq \mathrm{Rb}^{+} \leq \mathrm{Cs}^{+}$. This selectivity is different from that of the methyl and ethyl ethers of p-tert-butyloxacalix[3]arene [3,5], the reason for which is not clear at this stage. The selectivity shown by MOC3A-Me is quite similar to that for dibenzo-24-crown-8, although the former is inferior to the latter in extraction power; the $\log K_{\mathrm{ex}}$ values for the extraction of alkali metal picrates with dibenzo-24-crown-8 in dichloromethane are $3.56\left(\mathrm{Na}^{+}\right)$, $4.341\left(\mathrm{~K}^{+}\right), 4.41\left(\mathrm{Rb}^{+}\right)$, and $4.69\left(\mathrm{Cs}^{+}\right)$at $298 \mathrm{~K}[17]$.

The standard Gibbs free energy change of the extraction reaction $\mathrm{M}^{+}{ }_{\mathrm{w}}+\mathrm{L}_{\mathrm{o}}+\mathrm{A}_{\mathrm{w}}^{-} \rightarrow \mathrm{ML}^{+} \mathrm{A}^{-}{ }_{\mathrm{o}}$ can be calculated by $\Delta G_{\text {ex }}^{\circ}=-2.303 R T \log K_{\text {ex }}$. The values at $298 \mathrm{~K}$ are shown in Table 1 . The $\Delta G^{\circ}$ ex value can be considered as the sum of the standard Gibbs free energy change for the transfer of dissociated $\mathrm{M}^{+}$and $\mathrm{A}^{-}$ from the aqueous phase to the organic phase $\left(\Delta G_{\mathrm{tr}, \mathrm{M}+\mathrm{A}}^{\circ}\right)$ and that of the formation of the $\mathrm{ML}^{+} \mathrm{A}^{-}$complex from $\mathrm{M}^{+}, \mathrm{L}$, and $\mathrm{A}^{-}$in the organic phase $\left(\Delta G^{\circ}{ }_{\mathrm{MLA}, \mathrm{O}}\right)$. The values of $\Delta G_{\mathrm{tr}, \mathrm{M}+\mathrm{A}}^{\circ}[18]$ and $\Delta G^{\circ}{ }_{\mathrm{MLA}, \mathrm{o}}\left(=\Delta G_{\mathrm{ex}}^{\circ}-\right.$ $\left.\Delta G^{\circ}{ }_{\mathrm{tr}, \mathrm{M}+\mathrm{A}}\right)$ are also listed in Table 1 . It should be noted that the contributions from the dehydration of $\mathrm{M}^{+}$ and $\mathrm{A}^{-}$are not included in the $\Delta G^{\circ}{ }_{\mathrm{MLA}, \mathrm{o}}$ values but in the $\Delta G^{\circ}{ }_{\mathrm{tr}, \mathrm{M}+\mathrm{A}}$ values, because the cited values of $\Delta G^{\circ}{ }_{\mathrm{tr}, \mathrm{M}+\mathrm{A}}$ correspond to the transfer of $\mathrm{M}^{+}$and $\mathrm{A}^{-}$from water to dry dichloromethane in which the ions are not hydrated [18]. The sequence in $\Delta G^{\circ}{ }_{\mathrm{tr}, \mathrm{M}+\mathrm{A}}, \mathrm{Na}^{+}>>\mathrm{K}^{+}>\mathrm{Rb}^{+}>\mathrm{Cs}^{+}$, indicates that the larger alkali metal ions are more extractable owing to the lower hydration in the aqueous phase. On the other hand, the $\Delta G_{\text {MLA, o }}^{\circ}$ values vary in the reverse sequence, $\mathrm{Na}^{+}<<\mathrm{K}^{+}<\mathrm{Rb}^{+}<\mathrm{Cs}^{+}$, indicating that the ternary complex $\mathrm{ML}^{+} \mathrm{A}^{-}$of the smaller alkali metal ions is more stable in the organic phase. The sequence in $\Delta G^{\circ}{ }_{\text {ex }}, \mathrm{Na}^{+}>$ $\mathrm{K}^{+} \geq \mathrm{Rb}^{+} \geq \mathrm{Cs}^{+}$, is consistent with that in $\Delta G_{\mathrm{tr}, \mathrm{M}+\mathrm{A}}^{\circ}$. This is because the difference in the $\Delta G^{\circ}{ }_{\text {MLA,o }}$ values between two alkali metal ions is smaller than the corresponding difference in $\Delta G_{\mathrm{tr}, \mathrm{M}+\mathrm{A}}^{\circ}$. Namely, the extraction selectivity of MOC3A-Me for the alkali metal ions is governed by the extractability of the metal ions themselves.

The $\Delta G^{\circ}$ MLA,o values are, further, the sum of the standard Gibbs free energy change of complexation between $\mathrm{M}^{+}$and $\mathrm{L}$ in the organic phase and that of association of $\mathrm{ML}^{+}$and $\mathrm{A}^{-}$in the organic phase. Here we discuss the ability of MOC3A-Me to complex with alkali metal ions in the gas phase with the aid of DFT calculations. It is known that tri- $O$-alkylated oxacalix[3]arenes have two typical conformations, cone and partial-cone, as illustrated in Figure 3. By analogy from the results for p-tert-butyloxacalix[3]arene alkyl ethers [3], a rapid conversion between the conformations should occur in the case of MOC3A-Me. The standard Gibbs free energies at $298 \mathrm{~K}$ of these conformations were calculated by DFT. The results showed

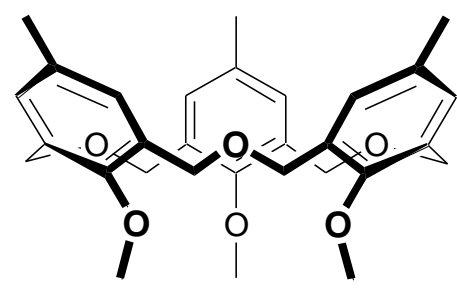

cone

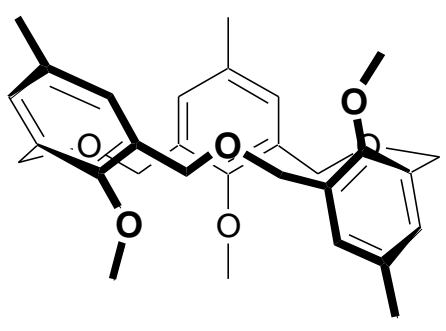

partial-cone

Figure 3. Typical conformations of MOC3A-Me. 
Table 2. Thermodynamic values calculated from DFT calculations to evaluate the standard Gibbs free energy change ( $\left.\Delta G^{\circ}{ }_{\mathrm{ML}+\text { gas }}\right)$ of the reaction $\mathrm{M}^{+}+\mathrm{L} \rightarrow \mathrm{ML}^{+}$in the gas phase at $298 \mathrm{~K}$.

\begin{tabular}{|c|c|c|c|c|c|}
\hline & & $\begin{array}{l}\text { Electronic energy } \\
\quad(\text { a.u. })^{a}\end{array}$ & $\begin{array}{l}\text { Thermal correction to } \\
\text { Gibbs free energy }{ }^{b} \\
\text { (a.u. })^{a}\end{array}$ & $\begin{array}{l}G_{298}{ }^{\circ} \\
{\text { (a.u. })^{a}}^{a}\end{array}$ & $\begin{array}{c}\Delta G_{\mathrm{ML+}, \mathrm{gas}}^{\circ} \\
(\mathrm{kJ} / \mathrm{mol})\end{array}$ \\
\hline \multirow[t]{4}{*}{$\mathrm{M}^{+}=$} & $\mathrm{Na}^{+}$ & -162.08123 & -0.01415 & -162.09538 & - \\
\hline & $\mathrm{K}^{+}$ & -27.97063 & -0.01488 & -27.98550 & \\
\hline & $\mathrm{Rb}^{+}$ & -23.70578 & -0.01596 & -23.72174 & \\
\hline & $\mathrm{Cs}^{+}$ & -19.73152 & -0.01659 & -19.74811 & \\
\hline $\mathrm{L}^{e}$ & & -1615.61202 & 0.52718 & -1615.61202 & - \\
\hline \multirow[t]{4}{*}{$\mathrm{ML}^{+e}=$} & $\mathrm{NaL}^{+}$ & -1778.37117 & 0.53119 & -1777.83998 & -348 \\
\hline & $\mathrm{KL}^{+}$ & -1644.17952 & 0.52739 & -1643.65213 & -143 \\
\hline & $\mathrm{RbL}^{+}$ & -1521.50318 & 0.52735 & -1639.37213 & -101 \\
\hline & $\mathrm{CsL}^{+}$ & -1517.51485 & 0.52629 & -1635.38459 & -64.2 \\
\hline
\end{tabular}

${ }^{a} 1$ a.u. $($ hartree $)=2625.5 \mathrm{~kJ} / \mathrm{mol}$

${ }^{b}$ Multiplied with a scaling factor of 0.9804 .

${ }^{c}$ Standard Gibbs free energy at $298 \mathrm{~K} ; G^{\circ}{ }_{298}=$ (electronic energy) + (thermal correction).

${ }^{d} \Delta G^{\circ}{ }_{\mathrm{ML}+\text {,gas }}=G^{\circ}{ }_{298}\left(\mathrm{ML}^{+}\right)-\left\{G^{\circ}{ }_{298}\left(\mathrm{M}^{+}\right)+G^{\circ}{ }_{298}(\mathrm{~L})\right\}$

${ }^{e} \mathrm{~L}=\mathrm{MOC} 3 \mathrm{~A}-\mathrm{Me}$ in the partial-cone conformation.

that the free MOC3A-Me molecule in the gas phase is $22.5 \mathrm{~kJ} \mathrm{~mol}^{-1}$ more stable in the partial-cone conformation than in the cone conformation; this finding agrees with the experimental results reported for p-tert-butyloxacalix[3]arene propyl ether [3]. It was also found that MOC3A-Me in the partial-cone conformation forms much more stable complexes with all the alkali metal ions than that in the cone conformation. Therefore, the dominant conformation of MOC3A-Me in both the free and complex forms is partial-cone. The standard Gibbs free energy change for the reaction $\mathrm{M}^{+}+\mathrm{L}$ (partial-cone) $\rightarrow \mathrm{ML}^{+}$ (partial-cone) in the gas phase at $298 \mathrm{~K}\left(\Delta G^{\circ}{ }_{\mathrm{ML}+\mathrm{gas}}\right)$ was calculated from the standard Gibbs free energies of $\mathrm{M}^{+}, \mathrm{L}$, and $\mathrm{ML}^{+}$. The thermodynamic values obtained are given in Table 2. The $\Delta G^{\circ}{ }_{\mathrm{ML}+\text {,gas }}$ value becomes more negative for the smaller alkali metal ions, which is explained in terms of the electrostatic interaction between the alkali metal ion and the ligand oxygen atoms. Such a variation of $\Delta G^{\circ}{ }_{\mathrm{ML}+\text {,gas }}$ is consistent with that of $\Delta G^{\circ}$ MLA,o in dichloromethane (Table 1), suggesting that the $\Delta G^{\circ}{ }_{\text {MLA,o }}$ value is governed by the intrinsic stability of $\mathrm{ML}^{+}$.

The equilibrium geometries of free MOC3A-Me and its complexes with $\mathrm{Na}^{+}$and $\mathrm{Cs}^{+}$are shown in Figure 4, where the ligand is in the partial-cone conformation. It is seen from the geometries that the ligand changes its conformation flexibly to effectively bind to the alkali metal ions of different sizes, where the number of the ligand oxygen atoms surrounding an alkali metal atom is always five. The standard Gibbs free energy at $298 \mathrm{~K}$ of the ligand having the conformation identical to that in the complex was calculated; the Gibbs free energy was found to vary with the complexing metal ion in the sequence, $\mathrm{Na}^{+}(-1615.59808$ 


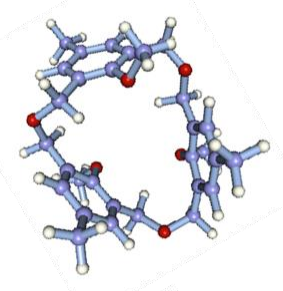

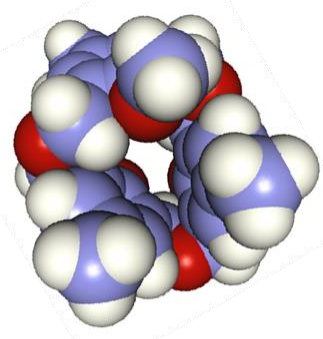

$\mathrm{L}$

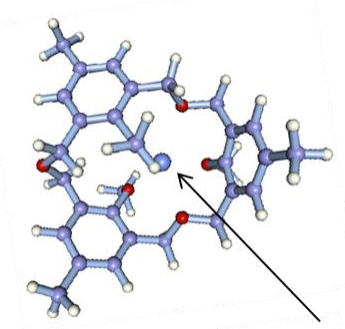

$\mathrm{Na}$ atom

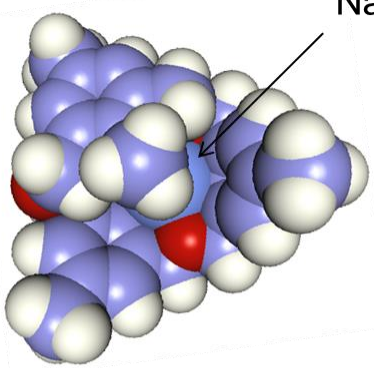

$\mathrm{NaL}^{+}$

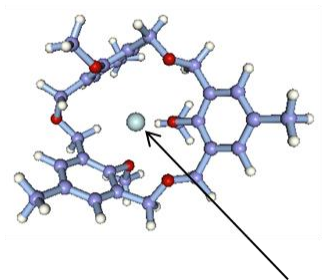

Cs atom

Figure 4. Equilibrium geometries of $\mathrm{L}, \mathrm{NaL}^{+}$, and $\mathrm{CsL}^{+}$in the gas phase determined by DFT calculations $(\mathrm{L}=\mathrm{MOC} 3 \mathrm{~A}-\mathrm{Me})$.

Upper drawing: ball and stick models

Lower drawing : space filling models

a.u. $)>\mathrm{K}^{+}(-1615.60101$ a.u. $) \approx \mathrm{Rb}^{+}(-1615.60031$ a.u. $)>\mathrm{Cs}^{+}(-1615.60291$ a.u.). This shows that the steric strain of the ligand arising from complexation is greater when the alkali metal ion is smaller. Such a steric strain should reduce the difference in the $\Delta G^{\circ}{ }_{\mathrm{ML}+\text {,gas }}$ values between the alkali metal ions.

\section{Conclusion}

$p$-Methyloxacalix[3]arene methyl ether exhibits an extraction selectivity for the larger alkali metal ion such as $\mathrm{Cs}^{+}$. The selectivity is governed by the extractability of the alkali metal ions themselves. The ligand has a flexible structure and changes its conformation to complex effectively with the alkali metal ions of different sizes. The ligand interacts more strongly with the smaller alkali metal ions having a higher charge density, but the ligand conformational strain upon complexation is also larger for the smaller alkali metal ions. Consequently, the complexation of the ligand with the alkali metal ions makes only a minor contribution to the extraction selectivity, although it should be effective in enhancing the extractability of the alkali metal ions. A similar explanation may hold true for the extraction selectivity of dibenzo-24-crown-8 [17]. On the other hand, we have recently reported a more highly $\mathrm{Cs}^{+}$-selective ionophore, the 1,1,1-tris[(salicylideneamino)methyl]ethane - aluminium(III) complex, which has a rigid cavity suited for accommodating $\mathrm{Cs}^{+}$[9]. It appears certain that the rigidity of the ligand structure is an important factor for enhancing the selectivity. 


\section{Acknowledgement}

This research was partially supported by research grants from the Futaba Electronic Memorial Foundation and AGSST of Chiba University.

\section{References}

1) K. Cottet, P. M. Marcos, P. J. Cragg, Beilstein J. Org. Chem., 8, 201-226 (2012).

2) K. Araki, N. Hashimoto, H. Otsuka, S. Shinkai, J. Org. Chem., 58, 5958-5963 (1993).

3) K. Araki, K. Inada, H. Otsuka, S. Shinkai, Tetrahedron, 49, 9465-9478 (1993).

4) P. D. Hampton, Z. Bencze, W. Tong, C. E. Daitch, J. Org. Chem., 59, 4838-4843 (1994).

5) K. Araki, H. Hayashida, Tetrahedron Lett., 41, 1807-1810 (2000).

6) P. M. Marcos, J. R. Ascenso, P. J. Cragg, Supramol. Chem., 19, 199-206 (2007).

7) P. M. Marcos, J. R. Ascenso, M. A. P. Segurado, R. J. Bernardino, P. J. Cragg, Tetrahedron, 65, 496-503 (2009).

8) X.-L. Ni, C.-C. Jin, X.-K. Jiang, M. Takimoto, S. Rahman, X. Zeng, D. L. Hughes, C. Redshaw, T. Yamato, Org. Biomol. Chem., 11, 5435-5442 (2013).

9) S. Katsuta, Y. Shimizu, R. Takahashi, N. Kanaya, T. Imoto, Y. Takeda, New J. Chem., 36, 1445-1448 (2012).

10) A. D. Becke J. Chem. Phys., 98, 5648-5652 (1993).

11) P. J. Stephens, F. J. Devlin, C. F. Chabalowski, M. J. Frisch, J. Phys. Chem., 98, 11623-11627, (1994).

12) M. J. Frisch, G. W. Trucks, H. B. Schlegel, G. E. Scuseria, M. A. Robb, J. R. Cheeseman, J. A. Montgomery, Jr., T. Vreven, K. N. Kudin, J. C. Burant, J. M. Millam, S. S. Iyengar, J. Tomasi, V. Barone, B. Mennucci, M. Cossi, G. Scalmani, N. Rega, G. A. Petersson, H. Nakatsuji, M. Hada, M. Ehara, K. Toyota, R. Fukuda, J. Hasegawa, M. Ishida, T. Nakajima, Y. Honda, O. Kitao, H. Nakai, M. Klene, X. Li, J. E. Knox, H. P. Hratchian, J. B. Cross, V. Bakken, C. Adamo, J. Jaramillo, R. Gomperts, R. E. Stratmann, O. Yazyev, A. J. Austin, R. Cammi, C. Pomelli, J. W. Ochterski, P. Y. Ayala, K. Morokuma, G. A. Voth, P. Salvador, J. J. Dannenberg, V. G. Zakrzewski, S. Dapprich, A. D. Daniels, M. C. Strain, O. Farkas, D. K. Malick, A. D. Rabuck, K. Raghavachari, J. B. Foresman, J. V. Ortiz, Q. Cui, A. G. Baboul, S. Clifford, J. Cioslowski, B. B. Stefanov, G. Liu, A. Liashenko, P. Piskorz, I. Komaromi, R. L. Martin, D. J. Fox, T. Keith, M. A. Al-Laham, C. Y. Peng, A. Nanayakkara, M. Challacombe, P. M. W. Gill, B. Johnson, W. Chen, M. W. Wong, C. Gonzalez, J. A. Pople, Gaussian 03, Revision D.01, Gaussian, Inc., Wallingford, 2004.

13) P. J. Hay, W. R. Wadt, J. Chem. Phys., 82, 299-310 (1985).

14) J. B. Foresman, A. Frisch, Exploring Chemistry with Electronic Structure Methods, 2nd ed., Gaussian, Inc., Pittsburgh, 2000.

15) L. Onsager, J. Am. Chem. Soc., 58, 1486-1493 (1936).

16) M. W. Wong, K. B. Wiberg, M. J. Frisch, J. Am. Chem. Soc., 114, 1645-1652 (1992).

17) Y. Takeda, R. Taguchi, S. Katsuta, J. Mol. Liq., 115, 139-147 (2004).

18) A. F. Danil de Namor, R. Traboulssi, F. F. Salazar, V. Dianderas de Acosta, Y. Fernández de Vizcardo, J. M. Portugal, J. Chem. Soc. Faraday Trans. 1, 85, 2705-2712 (1989). 